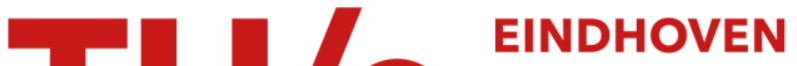 UNIVERSITY OF TECHNOLOGY
}

\section{Overcoming modal bandwidth limitation in radio-over- multimode fiber links}

\section{Citation for published version (APA):}

Garcia Larrode, M., Koonen, A. M. J., \& Vegas Olmos, J. J. (2006). Overcoming modal bandwidth limitation in radio-over-multimode fiber links. IEEE Photonics Technology Letters, 18(22), 2428-2430.

https://doi.org/10.1109/LPT.2006.886822

DOI:

10.1109/LPT.2006.886822

Document status and date:

Published: 01/01/2006

\section{Document Version:}

Publisher's PDF, also known as Version of Record (includes final page, issue and volume numbers)

\section{Please check the document version of this publication:}

- A submitted manuscript is the version of the article upon submission and before peer-review. There can be important differences between the submitted version and the official published version of record. People interested in the research are advised to contact the author for the final version of the publication, or visit the $\mathrm{DOI}$ to the publisher's website.

- The final author version and the galley proof are versions of the publication after peer review.

- The final published version features the final layout of the paper including the volume, issue and page numbers.

Link to publication

\section{General rights}

Copyright and moral rights for the publications made accessible in the public portal are retained by the authors and/or other copyright owners and it is a condition of accessing publications that users recognise and abide by the legal requirements associated with these rights.

- Users may download and print one copy of any publication from the public portal for the purpose of private study or research.

- You may not further distribute the material or use it for any profit-making activity or commercial gain

- You may freely distribute the URL identifying the publication in the public portal.

If the publication is distributed under the terms of Article 25fa of the Dutch Copyright Act, indicated by the "Taverne" license above, please follow below link for the End User Agreement:

www.tue.nl/taverne

Take down policy

If you believe that this document breaches copyright please contact us at:

openaccess@tue.nl

providing details and we will investigate your claim. 


\title{
Overcoming Modal Bandwidth Limitation in Radio-over-Multimode Fiber Links
}

\author{
M. García Larrodé, Student Member, IEEE, A. M. J. Koonen, Senior Member, IEEE, and \\ J. J. Vegas Olmos, Student Member, IEEE
}

\begin{abstract}
Employing the optical frequency multiplication method, the theoretical modal bandwidth limitation of multimode fiber (MMF) can be overcome in radio-over-fiber links. The principle is analyzed theoretically and supported experimentally by generation and transmission of microwave carriers up to $40 \mathrm{GHz}$ and 16- and 64-level quadrature-amplitude-modulated (QAM) radio signals in the 24- to $30-\mathrm{GHz}$ band over 4.4-km MMF link.
\end{abstract}

Index Terms-Multimode fiber (MMF), optical fiber communication, radio-over-fiber (RoF), wireless access networks.

\section{INTRODUCTION}

$\mathbf{T}$ HE USE of multimode fiber (MMF) for the last mile access networks has attracted much attention in the last years due to the MMF's dominant position in already installed fiber infrastructure inside buildings. Research efforts have been mainly dedicated to enhance baseband digital transmission performance of MMF links [1], as well as to develop low-cost radio-over-fiber (RoF) techniques for short MMF distances [2]. For the emerging broadband wireless systems operating at carrier frequencies in the microwave/millimeter wave bands, the theoretical modal bandwidth limit imposed by the well-known bandwidth-distance product, confines the use of MMF to very short links. Exploiting the passband transmission region of MMF, microwave signals can be transmitted over MMF links [3], but the passband region differs with fiber length variations, which might not be practical in the rollout of a radio-over-MMF-based infrastructure. Another method to overcome this theoretical bandwidth limitation is the optical frequency multiplication (OFM) principle [4]. Preliminary experiments have demonstrated the remote delivery of microwave signals up to $18 \mathrm{GHz}$ over an MMF link [5]. However, to our best knowledge, the fact of surpassing this theoretical modal bandwidth has not been explained accurately yet. In this letter, we investigate the OFM principle and its application to MMF transmission with some theoretical models. In addition, we present the results of an experimental analysis of the OFM performance for the generation of microwave carriers up to $40 \mathrm{GHz}$ and their transmission over an MMF link. Upconversion and transmission of M-ary quadrature-amplitudemodulated (M-QAM) radio signals in the 24- to $30-\mathrm{GHz}$ band is also demonstrated and compliant with the requirements of wireless standard IEEE 802.11a.

Manuscript received July 14, 2006; revised September 18, 2006. This work was supported by the IOP GenCom Program of Senter Novem (Dutch Ministry of Economics Affairs)

The authors are with the COBRA Research Institute, Eindhoven University of Technology, Eindhoven $5600 \mathrm{MB}$, The Netherlands.

Color versions of Figs. 2-4 are available online at http://ieeexplore.ieee.org.

Digital Object Identifier 10.1109/LPT.2006.886822

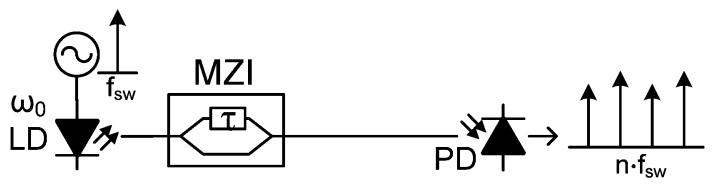

(a)

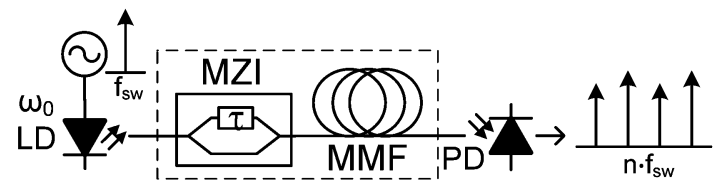

(b)

Fig. 1. OFM principle.

\section{THEORY}

\section{A. OFM Principle}

OFM is based on harmonics generation by frequency modulation to intensity modulation (FM-IM) conversion through a periodic bandpass filter. The frequency modulation of a light source $\omega_{0}$ by a sinusoid signal of sweep frequency $\omega_{\mathrm{sw}}$ can be represented by

$$
E_{\text {in }}(t)=E_{0} \cdot e^{j\left(\omega_{o} t+\beta \sin \left(\omega_{\mathrm{sw}} t\right)+\phi(t)\right)}
$$

where $\beta$ indicates the frequency modulation index and $E_{0}$ is the amplitude of the optical field.

When a Mach-Zehnder interferometer (MZI) with impulse response $h_{\mathrm{MZI}}(t)=1 / 2[\delta(t)+\delta(t-\tau)]$ is used as a periodic bandpass filter, and the resulting signal is launched into a photodiode [Fig. 1(a)], the intensity of the electrical signal obtained can be expressed as

$$
\begin{aligned}
i(t)=\frac{1}{2}\left|E_{0}\right|^{2} \cdot\left[1+\cos \left(\omega_{o} \tau\right.\right. & +\beta \sin \left(\omega_{\mathrm{sw}} t\right) \\
& \left.\left.-\beta \sin \left(\omega_{\mathrm{sw}}(t-\tau)\right)+\dot{\phi} \tau\right)\right]
\end{aligned}
$$

with $\dot{\phi} \tau=\phi(t)-\phi(t-\tau)$, where $\tau$ is the time delay in one of the arms of the MZI, and $\dot{\phi}$ indicates the laser phase noise contribution. Expanding (2) with Bessel functions of the first kind $\left(J_{n}\right)$, it can be seen that the signal at the output of the photodiode has frequency components at every harmonic $n \cdot \omega_{\mathrm{sw}}$ of the sweep frequency, with relative amplitudes

$$
\left.\begin{array}{r}
\cos \left(\left(\omega_{o}+\dot{\phi}\right) \tau\right) \cdot J_{2 n}\left(2 \beta \sin \left(\frac{\omega_{\mathrm{sw}} \tau}{2}\right)\right),(\text { even }) \\
\sin \left(\left(\omega_{o}+\dot{\phi}\right) \tau\right) \cdot J_{2 n-1}\left(2 \beta \sin \left(\frac{\omega_{\mathrm{sw}} \tau}{2}\right)\right),(\text { odd })
\end{array}\right\}
$$

for the even and the odd harmonics, respectively, and that the laser phase noise impact can be considered negligible as long as $\dot{\phi} \ll \pi / 2 \tau[4]$. 


\section{B. MMF Model and Total System Response}

According to [6], the response $h_{\mathrm{MMF}}(z, t)$ of an MMF at a position $z$ to an impulse launched at $z=0$ can be modeled as

$$
h_{\mathrm{MMF}}(z, t)=\sum_{k} \omega_{k} \cdot e^{\left(-\gamma_{k} z\right)} \cdot \delta\left(t-\tau_{k} z\right)
$$

where the set $\omega_{k}$ is the mode power distribution (MPD), $\gamma_{k}$ is the attenuation coefficient for mode $k$, and $\tau_{k}$ is the mode group delay (MGD) per-unit length. The corresponding transfer function is periodic against frequency, and its shape compresses with long fiber lengths and expands with short fiber lengths. This characteristic determines the well-known bandwidth-distance product $(\mathrm{BW} \cdot L)$, which theoretically limits the MMF bandwidth for baseband transmission to the first $-3-\mathrm{dB}$ fall.

In an OFM link, where the light source is frequency swept by $\omega_{\text {sw }}$, the theoretical BW $\cdot L$ product is not applicable like in baseband transmission links with continuous-wave light sources. Instead, the complete MMF frequency response in (4) has to be considered in combination with the MZI. As a result, the FM-IM conversion is performed through a total periodic filter determined by $h_{\mathrm{SYST}}(z, t)=h_{\mathrm{MZI}}(t) * h_{\mathrm{MMF}}(z, t)$ [Fig. 1(b)]. The transfer function $H_{\mathrm{SYST}}(z, f)$ of such a total filter is depicted in Fig. 2(d). In this example, the MZI shift delay is $\tau=100$ ps [Fig. 2(a)] and the MMF is modeled with the values of MPD and MGD indicated in Fig. 2(b) [6] (example for illustration purposes), which yield the MMF transfer function $H_{\mathrm{MMF}}(z, f)$ depicted in Fig. 2(c) for $z=4 \mathrm{~km}$ (attenuation is not included). As can be seen, the shape of the total periodic filter is mainly dictated by the MZI response, whereas the MMF introduces some ripple-patterns inside the dominating MZI lobes. In a real link, mode mixing between mode groups may occur due to transmission and connector offset. Each mode group output yields a combination of weighted versions of the input signal with corresponding path delay. As a result, the FM-IM conversion is performed in two steps: first, through the MZI (with $\tau$ ), and second, through the MMF link (with multiple $\tau_{i}$ combinations per mode group). Thus, the desired harmonic band can be optimized through the MMF with the parameters $\omega_{0}, \tau$, and $\beta$, which may help to alleviate the dramatic effect of dips in the (conventional) MMF frequency response.

\section{EXPERIMENTAL MEASUREMENTS}

To test the effects of MMF transmission in an RoF link based on OFM, an experimental arrangement according to the schematics in Fig. 1 was setup. A phase modulator was used to modulate the frequency of a continuous-wave laser source $(1310 \mathrm{~nm})$ by a sweep frequency $f_{\mathrm{sw}}$. The free-spectral range of the MZI was $10 \mathrm{GHz}(\tau=100 \mathrm{ps})$ and the photodiode had a $25-\mathrm{GHz}-3-\mathrm{dB}$ bandwidth. The fiber employed in the transmission was a 4.4-km-long 50- $\mu \mathrm{m}$-core graded-index MMF with $1.604-\mathrm{GHz} \cdot \mathrm{km} \mathrm{BW} \cdot L$ product and $0.49-\mathrm{dB} / \mathrm{km}$ attenuation at $1310 \mathrm{~nm}$. The output of the photodiode was boosted with a $40-\mathrm{GHz}$ broadband amplifier and visualized with a vector signal analyzer.

Fig. 3(a) shows the harmonic strength obtained after MMF transmission at the RF frequency multiples of $f_{\mathrm{sw}}$, with $f_{\mathrm{sw}}$ varying from 1 to $6 \mathrm{GHz}$. As indicated in (3), the relative amplitude of each harmonic depends on $f_{\mathrm{sw}}, \tau$, and $\beta$; thus, as-

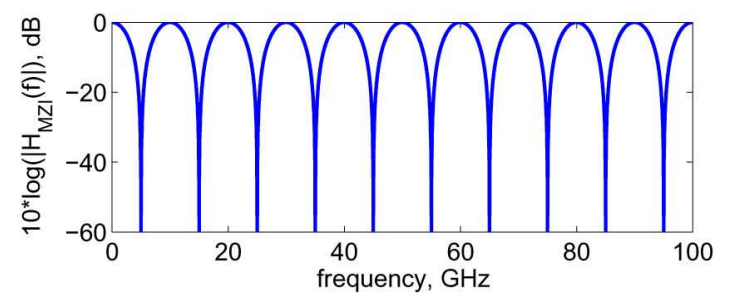

(a)
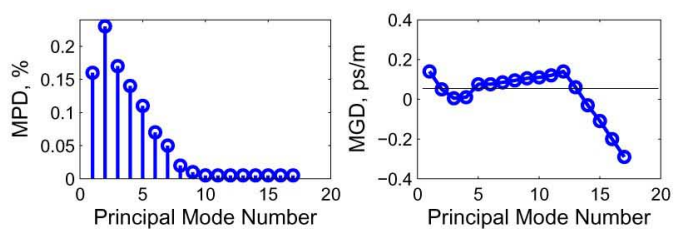

(b)

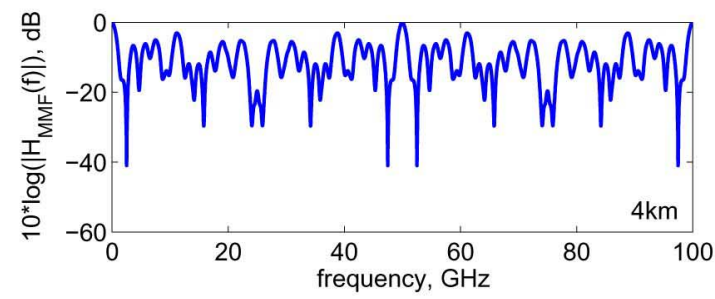

(c)

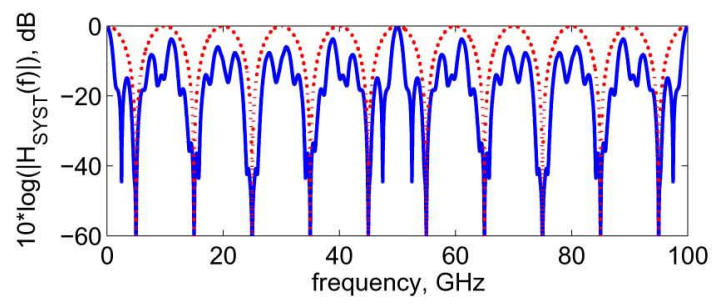

(d)

Fig. 2. System transfer functions: (a) MZI transfer function $\left|H_{\mathrm{MZI}}(f)\right|$ with $\tau=100 \mathrm{ps}$; (b) MMF characterization example (MPD and MGD); (c) MMF transfer function $\left|H_{\mathrm{MMF}}(z=4 \mathrm{~km} ; f)\right|$ corresponding to characteristics in (b); (d) total transfer function $\left|H_{\mathrm{SYST}}(z=4 \mathrm{~km} ; f)\right|$.

suming a fixed $\tau(\mathrm{MZI}), f_{\mathrm{sw}}$ and $\beta$ can be selected to optimize performance at the desired band. Fig. 3(b) shows the RF spectra measured at the output of the photodiode with $f_{\mathrm{sw}}=6 \mathrm{GHz}$. Comparing the measured spectra in the back-to-back case and after the MMF link, the envelope of the harmonics amplitude is preserved, and only slight fluctuations in the harmonic distribution power can be observed.

To evaluate the link performance for radio signals transmission and upconversion, the optical FM signal (with $f_{\mathrm{sw}}=6 \mathrm{GHz}$ ) was intensity modulated (externally) by 16-QAM and 64-QAM signals at $300 \mathrm{MHz}$, with symbol rates (SRs) ranging from 5 to $20 \mathrm{MS} / \mathrm{s}$ and error vector magnitude (EVM) values ranging from $0.5 \%$ to $1.8 \%$ (i.e., signal-to-noise ratio (SNR) from 46 to $34.9 \mathrm{~dB}$ ). Then, the RF signals obtained along with the fourth harmonic $\left(f_{4 \mathrm{th}}=24 \mathrm{GHz}\right)$ at $f_{\mathrm{RF}}=23.7 \mathrm{GHz}$, and with the fifth harmonic $\left(f_{5 \mathrm{th}}=30 \mathrm{GHz}\right)$ at $f_{\mathrm{RF}}=29.7 \mathrm{GHz}$, were selected for evaluation.

The SNR of the selected signals was derived from EVM measurements, in order to calculate the SNR degradation introduced by the RoF analog link. Fig. 4 shows the total SNR penalty expe- 


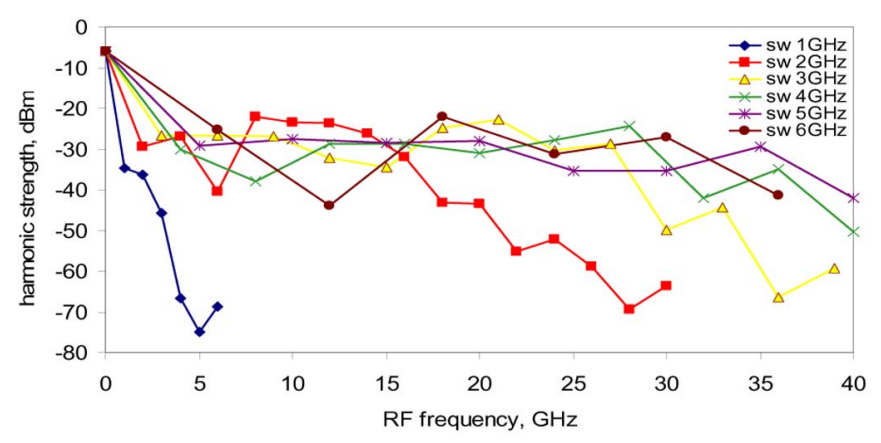

(a)
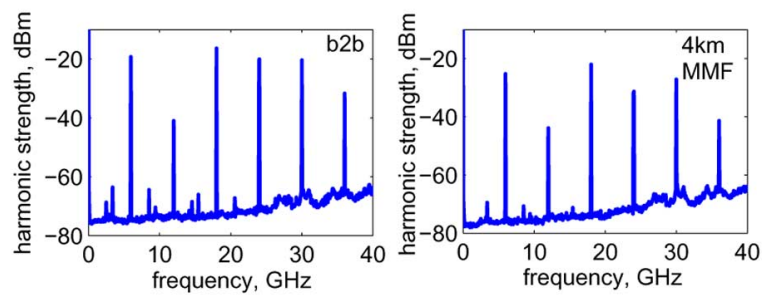

(b)

Fig. 3. Harmonics generation by OFM: (a) Harmonics strength with varying sweep frequency (sw); (b) spectra measurements with $f_{\mathrm{sw}}=6 \mathrm{GHz}$, back-toback (left) and after 4.4-km MMF transmission (right).
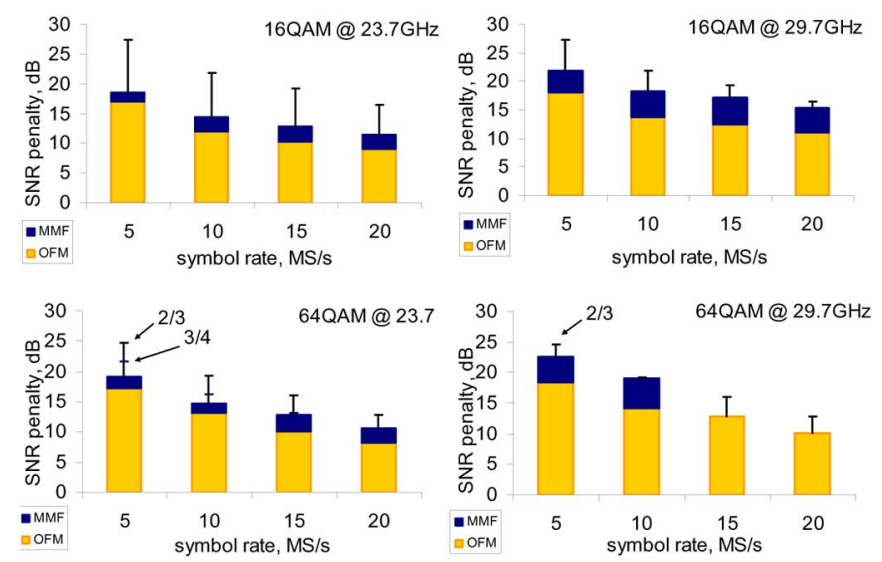

Fig. 4. SNR penalty experienced by the 16-QAM and 64-QAM signals recovered at 23.7 and $29.7 \mathrm{GHz}$ due to OFM upconversion (OFM) and MMF transmission (MMF).

rienced by the 16-QAM and 64-QAM signals recovered at 23.7 and $29.7 \mathrm{GHz}$, indicating the penalty contribution due to OFM upconversion with respect to the input signals at $300 \mathrm{MHz}$ and due to MMF transmission, separately. The SNR penalty margin to comply with the IEEE802.11a standard specification for the transmitter constellation error (i.e., 5.6\% and 7.9\% for 64-QAM with code rate $3 / 4$ and $2 / 3$, respectively; and $11.2 \%$ for 16 -QAM with code rate 3/4) is also indicated with error bars.

The SNR degradation due to OFM upconversion does not depend on the QAM constellation, but on the signal bandwidth SR. The lower OFM upconversion SNR penalty observed with higher SR occurs because the effective modulation index of the intensity modulator varies with SR and the phase noise contribution, which is higher for higher SR in the input signals, and does not scale linearly in terms of SNR penalty. However, the SNR penalty margin is still narrower for higher SR because the input signals at $300 \mathrm{MHz}$ also had worse SNR for higher SR. The SNR penalty caused by MMF transmission was $\sim 2.4$ and $\sim 4.5 \mathrm{~dB}$ for the signals recovered at 23.7 and $29.7 \mathrm{GHz}$, respectively. The different performance observed for the signals at 23.7 and $29.7 \mathrm{GHz}$ has three main penalty sources: first, the average power distributed to the fourth and the fifth harmonics is different; second, the fifth harmonic $(30 \mathrm{GHz})$ lies $5 \mathrm{GHz}$ beyond the nominal photodiode bandwidth, thus, the photodiode response at $29.7 \mathrm{GHz}$ is less efficient; and third, the $40-\mathrm{GHz}$ broadband amplifier employed in the experiment produced a noise peak in the band around $30 \mathrm{GHz}$ [see noise profile in Fig. 3(b)], which introduced additional distortion in the signals recovered in this band.

As can be seen in Fig. 4, the 16-QAM signals meet the standard requirements in all cases. For 64-QAM, a maximum of $10 \mathrm{MS} / \mathrm{s}$ at $29.7 \mathrm{GHz}$ could be successfully transmitted according to the more strict requirements (though the backto-back upconversion was successful in all the cases). In order to comply with the standard specification for the $20-\mathrm{MS} / \mathrm{s}$ 64-QAM signals at $29.7 \mathrm{GHz}$, the input signals at $300 \mathrm{MHz}$ should have an SNR better than 40 and $37 \mathrm{~dB}$ for $3 / 4$ and 2/3 code rates, respectively.

\section{CONCLUSION}

In this letter, we have demonstrated how, by employing the OFM technique, the modal bandwidth limitation of an MMF link can be overcome in RoF systems. The experiments reported here show that OFM can be applied to generate microwave carriers up to $40 \mathrm{GHz}$ and distribute them over $4.4 \mathrm{~km}$ of MMF link. Also, 16-QAM and 64-QAM radio signals are upconverted from $300 \mathrm{MHz}$ to $23.7 \mathrm{GHz}$ and $29.7 \mathrm{GHz}$, and recovered successfully after the MMF link. Results suggest that the system performance is not jeopardized by modal dispersion, and that any length of MMF could be used, provided that the power budget is properly dimensioned. Thus, the RF bandwidth limit of the link is determined by the distance between generated harmonics, i.e., the sweep frequency, which is an adjustable system parameter.

\section{REFERENCES}

[1] L. Raddatz, I. White, D. Cunningham, and M. Nowell, "An experimental and theoretical study of the offset launch technique for the enhancement of the bandwidth of multimode fiber links," J. Lightw. Technol., vol. 16, no. 3, pp. 324-331, Mar. 2002.

[2] P. Hartmann, X. Qian, R. Penty, and I. White, "Broadband multimode fibre (MMF) based IEEE $802.11 \mathrm{a} / \mathrm{b} / \mathrm{g}$ WLAN distribution system," in Proc. Int. Topical Meeting Microwave Photonics (MWP'04), Ogunquit, ME, Oct. 2004, pp. 173-176.

[3] P. Hartmann, X. Qian, A. Wonfor, R. Penty, and I. White, " $1-20 \mathrm{GHz}$ directly modulated radio over MMF link," in Proc. Int. Topical Meeting Microwave Photonics (MWP'05), Seoul, Korea, Oct. 2005, pp. 95-98.

[4] A. M. J. Koonen and A. Ngoma, "Integrated broadband optical fibre/ wireless LAN access networks," in Broadband Optical Access Networks and Fiber-to-the-Home: System Technologies and Development Strategies. New York: Wiley, 2006, ch. 11.

[5] M. G. Larrode, A. M. J. Koonen, J. J. V. Olmos, and A. Ngoma, "Bidirectional radio-over-fiber link employing optical frequency multiplication," IEEE Photon. Technol. Lett., vol. 18, no. 1, pp. 241-243, Jan. 1, 2006.

[6] P. Pepeljugoski, S. E. Golowich, A. J. Ritger, P. Kolesar, and A. Risteski, "Modeling and simulation of next-generation multimode fiber links," J. Lightw. Technol., vol. 21, no. 5, pp. 1242-1255, May 2003. 